\title{
A RESPONSABILIDADE CIVIL DE MÉDICOS E DE INSTITUIÇÕES DA ÁREA MÉDICA
}

The civil responsibility of physicians and institutions in the medical field

${ }^{1}$ Universidade de São Paulo. São Paulo/SP, Brasil.

Correspondência: Dalmo de Abreu Dallari. E-mail: revdisan@usp.br.

Recebido em: 08/10/2015. 
1. Os trabalhos aqui reunidos tratam, essencialmente, da questão da responsabilidade civil de médicos e de instituições da área médica. Eles consideram esse problema sob diferentes perspectivas, mas todos buscam analisar a questão da responsabilidade civil mediante a aplicação dos preceitos constantes do Código Civil brasileiro, tendo em conta problemas concretos que têm chegado aos tribunais - que, por sua vez, ensejam debates e levam a decisões cujos fundamentos também são aqui questionados.

Na realidade, há muitas divergências nas considerações teóricas, assim como nas decisões judiciais e nas considerações de ordem prática, sendo oportuno colocar o tema em debate para estimular análises e reflexões que hoje têm muita importância dos pontos de vista teórico e prático. Um dado concreto que faz ressaltar essa importância é o fato de que aumentou muito, nas últimas décadas, o número de questões judiciais relacionadas com as práticas médicas e hospitalares - fato este que envolve também um questionamento sobre as responsabilidades dos poderes públicos, tendo em conta os preceitos constitucionais sobre a responsabilidade pela garantia, proteção, promoção e efetivação do direito à saúde.

A projeção da saúde como direito fundamental da pessoa humana e a consequente busca de definições quanto à responsabilidade dos médicos relativa ao respeito e à proteção do direito à saúde surgiram logo após o término da Segunda Guerra Mundial. Mais especificamente, essas questões foram suscitadas e ganharam grande ênfase nas acusações e nos debates que se colocaram no Tribunal de Nuremberg, instituição criada pelas potências vencedoras da guerra e instalada na cidade de Nuremberg, na Alemanha. Um tema que foi tratado com grande relevância naquele tribunal foi a realização de experiências, com brutalidade e sem qualquer consideração de natureza ética, com seres humanos para obtenção e desenvolvimento de conhecimentos científicos e para o desenvolvimento de tecnologias, substâncias e aparelhamento para utilização na área médica e médico-hospitalar. No dia 9 de dezembro de 1946 teve início o julgamento de 23 pessoas responsáveis por aquelas práticas, 20 das quais eram médicos; todas foram consideradas criminosas de guerra. Sete desses acusados foram condenados à pena de morte e executados, mas, a par disso e tendo em conta os dados obtidos durante o julgamento, foi elaborado um documento fixando regras a respeito da utilização de pessoas em experimentos científicos. Esse documento recebeu a denominação de Código de Nuremberg e, desde então, passou a influir no exame e na avaliação das práticas de utilização de seres humanos em busca da ampliação de conhecimentos científicos. Foi aí que se estabeleceu a regra básica, hoje universalmente consagrada, segundo a qual, nenhum experimento com seres humanos poderá ser realizado sem o prévio consentimento voluntário, livre e informado daquela pessoa que será sujeito da pesquisa. Essa exigência se aplica a pessoas e instituições que se dediquem a pesquisas científicas com seres humanos, e também às autoridades públicas responsáveis pela integridade física e pelos valores éticos da pessoa humana. 
Depois disso e considerando as informações obtidas pelo Tribunal de Nuremberg e as normas consagradas no Código de Nuremberg, a 18 a Assembleia Médica Mundial, reunida em 1964 na cidade de Helsinque, na Finlândia, aprovou outro documento, identificado como Declaração de Helsinque. Este documento foi consagrado como a primeira grande contribuição da comunidade médica para regulamentar o desempenho dos médicos nas atividades de pesquisa científica. Na introdução da Declaração, proclama-se que "a Associação Médica Mundial desenvolveu a Declaração de Helsinque como uma declaração de princípios éticos para fornecer orientação aos médicos e outros participantes em pesquisas clínicas envolvendo seres humanos".

Esses documentos são importantes para orientar as práticas médicas relacionadas tanto com a pesquisa científica quanto com a pesquisa clínica e, por isso, devem ser divulgados e levados ao conhecimento de todos aqueles - médicos ou coadjuvantes - que participam de atividades de pesquisa com seres humanos. Além disso, esses documentos tiveram influência nas legislações nacionais e, sem dúvida, influíram para que a Constituição brasileira de 1988 desse grande ênfase à saúde, proclamando-a "direito de todos e dever do Estado", como está expresso no artigo 196 da Constituição Federal de 1988². A par disso, todo o sistema jurídico deve ser coerente com esses preceitos, e assim deverão ser feitas as considerações sobre os trabalhos aqui reunidos. O Código Civil, por exemplo, tem disposições que, mesmo sendo de caráter mais geral e não direcionadas especificamente às questões de saúde, interessam a essas questões, sendo importantes o conhecimento dos preceitos vigentes e a compreensão de seu significado. Como se verá em seguida, cada um dos trabalhos aqui reunidos enfatiza determinados aspectos da legislação, tendo em conta ocorrências concretas mais frequentes que já levaram a questionamentos perante o Judiciário ou que deverão ser objeto de análise.

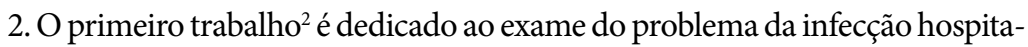
lar e da responsabilização civil nos tribunais brasileiros. A infecção hospitalar tem hoje grande amplitude no Brasil, ensejando muitos debates e inúmeras decisões judiciais a respeito da responsabilidade civil decorrente de sua ocorrência. Um problema que se tem colocado é a fixação da responsabilidade civil por tais anomalias registradas nos estabelecimentos destinados a cuidar da saúde das pessoas. Os pacientes são levados a esses locais para receberem cuidados médicos e acabam sendo afetados por infecção hospitalar, o que sempre acarreta prejuízos de várias espécies, de menor ou maior monta. E se indaga quem é que deve responder por tais prejuízos: o médico incumbido do paciente e geralmente o responsável por seu encaminhamento à instituição onde acabou sendo vítima da infecção ou a instituição responsável pelo local?

${ }^{1}$ BRASIL. Constituição da República Federativa do Brasil de 1988. Disponível em: <http://www.planalto.gov. br/ccivil_03/Constituicao/ConstituicaoCompilado.htm>. Acesso em: 07 out. 2015.

2 SILVA, José Marcio Carvalho. Infecção hospitalar e a responsabilização civil nos tribunais brasileiros. Revista de Direito Sanitário, São Paulo, v. 16, n. 2, p. 84-100, jul./out. 2015. http://dx.doi.org/10.11606/ issn.2316-9044.v16i2p84-100. 
Evidentemente, podem estar presentes vários fatores no encaminhamento do paciente àquele local, assim como na existência dos fatores que ocasionaram a infecção. Do ponto de vista legal, o ponto de partida para uma eventual atribuição de responsabilidade civil é o que dispõe expressamente o Código Civil em seu artigo 949: "No caso de lesão ou outra ofensa à saúde o ofensor indenizará o ofendido das despesas de tratamento e dos lucros cessantes até o fim da convalescença, além de algum outro prejuízo que o ofendido tenha sofrido"'s. Aí está um começo de resposta para as dúvidas jurídicas, pois o responsável, nos termos desse dispositivo legal, é "o ofensor", mas a partir daí pode-se iniciar uma discussão para a identificação do ofensor em determinado caso concreto.

Como foi bem assinalado nesse trabalho, um dos problemas é a distinção entre a responsabilidade do médico e a da instituição onde o paciente foi para receber tratamento e adquiriu a infecção. É preciso verificar se a instituição foi negligente no cuidado do local e, por sua negligência, deu causa ao surgimento dos fatores causadores da infecção. Mas, a par disso, a instituição poderá ter sido vítima da negligência de seus servidores incumbidos dos cuidados do local. Pode-se abrir, então, outro ângulo de discussão, indagando-se se a instituição tinha conhecimento da existência de más condições no local, ou se ela, pura e simplesmente, ignorou esse ponto e não tomou o cuidado necessário para que se mantivessem boas condições. Em tais hipóteses, se constatado que a instituição não adotou as providências necessárias e previsíveis, que deveria ter adotado, para evitar o risco de infecção, ela terá culpa pela ocorrência, caracterizando-se aí a responsabilidade subjetiva. Mas também poderá ser alegado que, mesmo tendo adotado a prevenção recomendável, ela não conseguiu impedir a ocorrência da infecção, podendo-se, então, argumentar que houve culpa objetiva da instituição, pelo simples fato de que ela era a responsável pelo local onde a infecção foi adquirida. Essa é a hipótese de responsabilidade civil objetiva.

Em outra perspectiva, pode-se questionar a responsabilidade do médico, indagando-se se ele verificou, antes de encaminhar para lá o paciente, se o local era apropriado, se ele tinha conhecimento das condições em que o paciente iria receber o tratamento. $\mathrm{O}$ que poderia eventualmente ser alegado é que o médico não teve o cuidado de verificar previamente as condições do local. Nesse caso, terá havido culpa do médico, ou responsabilidade objetiva. Ou, então, mais grave ainda, pode-se eventualmente alegar que ele tinha conhecimento de que a instituição era negligente e o local apresentava risco e, assim mesmo, enviou para lá o paciente. Nesta última hipótese, haverá responsabilidade civil subjetiva do médico.

Além desses aspectos, existe ainda um questionamento a respeito do relacionamento do paciente com o prestador dos serviços que receberia naquele local

${ }^{3}$ BRASIL. Lei n. 10.406, de 10 de janeiro de 2002. Institui o Código Civil. Disponível em: <http://www.planalto.gov.br/ccivil_03/LEIS/2002/L10406.htm>. Acesso em: 07 out. 2015. 
em que adquiriu a infecção. A questão que poderá ser colocada é se o paciente só tinha relação com o médico que o encaminhou ao local ou se ele estabeleceu relações com a instituição responsável pelo local. Esse é um problema paralelo que poderá ser suscitado caso a instituição queira eximir-se de responsabilidade, alegando que não tinha vínculo com o paciente, mas apenas com o médico que fazia os encaminhamentos de pacientes para o local.

Em síntese, o que se verifica é que são vários os aspectos que poderão ser considerados para a fixação da responsabilidade civil pela aquisição de infecção num determinado estabelecimento hospitalar. Uma das hipóteses possíveis é que ocorra, simultaneamente no mesmo caso, a responsabilização do médico e da instituição - tendo-se aí um caso de responsabilidade solidária, perfeitamente legal. É também oportuno observar que, no questionamento de ocorrências às vezes aparentemente semelhantes submetidas à decisão dos juízes, poderão ser usados, simultaneamente, diferentes argumentos e diversos meios de prova, o que poderá levar a decisões diferenciadas, não significando que tenha havido mudança de orientação ou, então, contradição dos julgadores.

3. Quando submetida ao Judiciário uma divergência a respeito da responsabilidade civil pelas más consequências de um determinado procedimento médico, é comum que surjam questionamentos a respeito da apuração das responsabilidades. E, nesses casos, é geralmente decisiva a prova pericial ${ }^{4}$, por meio da qual os julgadores são informados sobre as peculiaridades do caso e influenciados sobre a atribuição de responsabilidades.

Antes de tudo, é importante assinalar que, do ponto de vista legal, existe no Código de Processo Civil uma especificação dos meios de prova que poderão ser admitidos, não havendo, entretanto, uma classificação dos meios que podem ser utilizados como de maior ou menor importância. A restrição aos meios de prova encontra-se expressa no artigo $5^{\circ}$, inciso LVI, da Constituição, segundo o qual "são inadmissíveis, no processo, as provas admitidas por meio ilícito”. Caso seja apresentada alguma prova com esse defeito insanável, o juiz deverá ignorá-la e considerá-la como inexistente. No tocante aos meios admissíveis, o Código de Processo Civil especifica os seguintes: depoimento pessoal (artigos 342 a 347), exibição de documentos ou coisa (artigos 355 a 363), prova documental (artigos 364 a 399), confissão (artigos 348 a 354), prova testemunhal (artigos 400 a 419), inspeção judicial (artigos 440 a 443 ) e, finalmente, prova pericial (artigos 420 a 439).

Assim, a prova pericial é uma das que podem ser produzidas e tem o mesmo valor das demais, podendo ainda ocorrer que seja utilizado mais de um meio de

${ }^{4}$ KALLAS FILHO, Elias; FONSECA, João Paulo de Oliveira. A influência da prova pericial nas decisões judiciais acerca da responsabilidade civil dos médicos. Revista de Direito Sanitário, São Paulo, v. 16, n. 2, p. 101-115, jul./out. 2015. http://dx.doi.org/10.11606/issn.2316-9044.v16i2p101-115. 
prova para fazer a comprovação de determinado fato ou determinada circunstância. Quanto à importância e influência da prova pericial, cabe ao juiz fazer a avaliação e dar à perícia o valor probatório que, segundo essa avaliação, ela mereça. Obviamente, o juiz deverá levar em conta a qualificação técnica do perito, assim como a clareza e objetividade dos dados e a fundamentação dada pelo próprio perito para afirmar ou negar determinada peculiaridade ou circunstância. Nos casos em que, para melhor avaliação dos elementos probatórios apresentados, existir a necessidade de conhecimentos especializados, como são os casos relativos à responsabilidade de um médico ou de uma instituição hospitalar, é lógico e natural que o juiz seja influenciado pela perícia, a qual, se pressupõe, ser a conclusão de um especialista. Isso é, precisamente, o que ocorre com relação à perícia médica. $\mathrm{O}$ juiz não deverá admitir automaticamente como válidas e incontestáveis as conclusões do perito, mas cabe a ele, juiz, proceder ao exame e à avaliação e utilizar a prova pericial para formar seu convencimento, sua persuasão racional, para tomar a decisão.

Por todas essas razões, não é surpreendente nem suscetível de dúvidas o fato de que, na maioria dos casos em que foi efetuada a perícia médica, as conclusões do juiz coincidam com as da prova pericial. Como já foi observado, não existe uma classificação dos meios de prova para lhes atribuir maior ou menor valor. Assim sendo, a prova pericial tem o mesmo valor das demais, cabendo ao juiz, na formação de sua convicção, examinar racionalmente todas as provas apresentadas, fazendo sua análise e confrontação para construir racionalmente sua convicção. E quando, a par de outras, existir prova pericial - como nos casos em que se utiliza, em conjugação com outros meios, a perícia médica -, é razoável que as conclusões do juiz coincidam com as do perito.

4. No julgamento dos casos que lhe são submetidos relativos a pesquisas com seres humanos ${ }^{5}$, há o pressuposto de que, para formar sua convicção e proferir o julgamento, o juiz leve em conta os preceitos éticos relativos à pessoa humana, assim como as normas jurídicas que devem ser consideradas para o julgamento do caso. Com relação aos pesquisadores da área médica, é pouquíssimo provável que não tenham conhecimento da existência de preceitos éticos já consagrados, muitos deles proclamados e difundidos a partir de documentos fundamentais da humanidade, como o Código de Nuremberg e a Declaração de Helsinque. Além desses documentos de abrangência universal, estão em vigor outros documentos aprovados e postos em prática pelas instituições nacionais que estabelecem princípios e normas para o exercício das atividades médicas, como o Conselho Nacional de Saúde.

Uma observação que se tem feito é que existe um conhecimento insuficiente dos preceitos éticos e jurídicos por parte dos pesquisadores da área médica. Na realidade, existe na prática uma espécie de isolamento dos especialistas em suas

\footnotetext{
${ }^{5}$ TOMASEVICIUS FILHO,Eduardo. O Código Civil brasileiro na disciplina da pesquisa com seres humanos. Revista de Direito Sanitário, São Paulo, v. 16, n. 2, p. 116-146, jul./out. 2015. http://dx.doi.org/10.11606/ issn.2316-9044.v16i2p116-146.
} 
respectivas áreas de especialidade. Esse é um aspecto de natureza prática que deve ser considerado para que se proponha e estimule a busca de ampliação dos conhecimentos - não a ponto de se pretender que os pesquisadores da área médica façam cursos jurídicos, mas apenas chamando sua atenção para a necessidade de se aconselharem com especialistas e de procurarem obter alguns conhecimentos básicos sobre as disposições jurídicas relacionadas com as atividades de pesquisa. Pelas mesmas razões, é necessário e se tem dito com frequência que os juízes procurem estar mais bem informados a respeito das questões básicas relativas ao desempenho dos peritos da área médica, para que possam decidir com absoluta segurança e apliquem adequadamente a prova pericial.

Em conclusão, os temas aqui debatidos são de fundamental importância e de grande atualidade e foram abordados com segurança e responsabilidade pelos autores dos trabalhos. Assim sendo, pode-se afirmar que os debates aqui reunidos são uma contribuição valiosa para a difusão de conhecimentos e o estímulo de reflexões sobre a temática da responsabilidade civil na área médica e da busca de uma solução bem fundamentada e justa para a solução de conflitos que decorram de atividades de médicos e de instituições da área médica.

\section{Referências}

KALLAS FILHO, Elias; FONSECA, João Paulo de Oliveira. A influência da prova pericial nas decisões judiciais acerca da responsabilidade civil dos médicos. Revista de Direito Sanitário, São Paulo, v. 16, p. 84-100, jul./out. 2015. http://dx.doi.org/10.11606/issn.2316-9044.v16i2p84-100.

SILVA, José Marcio Carvalho. Infecção hospitalar e a responsabilização civil nos tribunais brasileiros. Revista de Direito Sanitário, São Paulo, v. 16, n. 2, p. 101-115, jul./out. 2015. http://dx.doi.org/10.11606/issn.2316-9044.v16i2p101-115.

TOMASEVICIUS FILHO,Eduardo. O Código Civil brasileiro na disciplina da pesquisa com seres humanos. Revista de Direito Sanitário, São Paulo, v. 16, n. 2, p. 116-146, jul./out. 2015. http://dx.doi.org/10.11606/issn.2316-9044.v16i2p116-146.

Dalmo de Abreu Dallari - Professor emérito da Faculdade de Direito da Universidade de São Paulo. Sao Paulo/SP, Brasil.E-mail: revdisan@usp.br. 